\title{
Easing Infants' Transition to Center-Based Child Care Using a Video-Feedback Intervention for Professional Caregivers and Parents: A Feasibility Study
}

Claudia I. Vrijhof ${ }^{1 *}$, Sanne M. de Vet ${ }^{*}$, Shelley M. C. van der Veek ${ }^{1}$, Hedwig J. A. van Bakel $^{2}$, Harriet J. Vermeer ${ }^{1}$

\footnotetext{
${ }^{1}$ Institute of Education and Child Studies, Leiden University, Leiden, the Netherlands

${ }^{2}$ Department of TRANZO, Tilburg School of Social and Behavioral Sciences, Tilburg University, Tilburg, the Netherlands
}

* Claudia Vrijhof and Sanne de Vet are joint first authors Corresponding author: Harriet Vermeer (vermeer@fsw.leidenuniv.nl) 


\begin{abstract}
The current study investigated the feasibility and potential indications for effectiveness of the Video-feedback Intervention to promote Positive Parenting - Transition to Infant Child Care (VIPP-TICC), which aims to promote professional caregivers' sensitivity and ease the transition to child care for infants and their parents. In total, 11 infants, professional caregivers and parents participated; four triads were randomly assigned to the intervention group and seven to the control group. The content, practical aspects and impact of the VIPPTICC on the professional caregiver, infant and parent, as well as the alliance with the intervener were overall positively evaluated by professional caregivers and parents. Despite these positive evaluations, descriptive statistics of the pre- and post-test assessments did not point to indications for differences in professional caregivers' sensitivity, infant well-being and attachment security to the professional caregiver in favor of the intervention group. Regarding parents, the descriptive statistics suggested a somewhat higher decrease in maternal separation anxiety over time, and slightly higher levels of perceived quality of care towards the infant in the intervention group. The current study indicates that especially the implementation of a single session with the professional caregiver and parent might be an interesting direction for further research and practice.
\end{abstract}

Key words: transition to child care, intervention, caregiver sensitivity, infant well-being, parental separation anxiety 


\section{Introduction}

The transition to center-based child care is a major step for children and their parents. Children need to get used to a group setting and multiple unfamiliar caregivers, which can be emotionally challenging. This challenge is reflected by signs of behavioral distress at child care as well as a rise in cortisol levels at child care from mid-morning to mid-afternoon as opposed to declining levels at home, both during the transition period and beyond (Ahnert et al., 2004; Albers et al., 2016; Bernard et al., 2015; De Vet et al., 2021a; Dettling et al., 1999; Vermeer \& Groeneveld, 2017). The transition to child care might be especially stressful for infants, since children seem to be most reactive to (mild) stressors in the first year of life (Gunnar \& Cheatham, 2003; Gunnar \& Donzella, 2002). Although experiencing some stress during the transition can be considered adaptive, very high stress levels and frequent and/or prolonged overactivation of the hypothalamic-pituitary-adrenal axis (HPA-axis) should be prevented. Overactivation of the HPA-axis is thought to have detrimental effects on the developing brain of young children, especially under the age of one (Tryphonopoulos et al., 2014), as well as on physiological, emotional, and behavioral processes (Essex et al., 2002; Gunnar \& Donzella, 2002).

Since infants do not have the capacity to independently regulate their emotions, they rely heavily on their caregivers to help them deal with stress (Kopp, 1989; Murray et al., 2015). Therefore, professional caregivers might play a key role in easing infants' start in child care. Successful co-regulation of infants' emotions requires warm and responsive interactions with caregivers (Murray et al., 2015), i.e. caregiver sensitivity, which can be defined as the ability to perceive infant signals, interpret these signals correctly, and respond to these signals promptly and appropriately (Ainsworth et al., 1978). Previous studies showed that sensitivity of the professional caregiver was positively related to children's well-being at child care (De Kruijf et al., 2007) and attachment security to the professional caregiver (Howes et al., 1998). 
Furthermore, it was found that children with secure attachments to their professional caregiver were more likely than insecurely attached children to exhibit the expected decline in cortisol levels across the child care day (Badanes et al., 2012; Eckstein-Madry et al., 2020). Although one might expect that the level of sensitivity of the professional caregiver towards a specific infant increases during the transition period because they get to know the infant better, this was not found in previous research (Albers et al., 2007).

Based on these findings, we set up a randomized controlled trial (RCT; see also the study registration in the Netherlands Trial Register (registration number: NL7647) investigating the effectiveness of the Video-feedback Intervention to promote Positive Parenting - Transition to Infant Child Care (VIPP-TICC) in increasing professional caregivers' sensitivity as well as decreasing infants' cortisol levels and promoting infants' well-being and attachment security to the professional caregiver. The VIPP-TICC is based on the Video-feedback Intervention to promote Positive Parenting and Sensitive Discipline (VIPP-SD; Juffer et al., 2008), a preventive intervention program for caregivers of children aged 1 to 6 years, which has been proven to be effective in enhancing caregiver sensitivity in different populations (Juffer et al., 2017), including professional caregivers in center-based child care settings (VIPP-CC; Werner et al., 2018). However, VIPP-CC targets professional caregivers of children between the age of 1 to 4 , and focuses on enhancing caregiver sensitivity towards a small group of children, whereas VIPP-TICC targets professional caregivers who take care of infants and focuses on enhancing caregivers' sensitivity in oneon-one interactions. By implementing the intervention directly after the start of an infant at the child care center (CCC) and closely monitoring them during the transition period, the VIPP-TICC ultimately aims to ease infants' transition to center-based child care (which is reflected by lower cortisol levels and higher levels of well-being) and to promote attachment 
security to the professional caregiver. Furthermore, we aimed to promote the quality of care towards the infant provided by the professional caregiver as perceived by the parent.

This aim relates to the secondary goal of the intervention to ease the transition to center-based child care for the primary parent of the infant (i.e. the parent that takes care of the infant most of the time, referred to as 'the parent' from here on), since the start of the infant in child care can be emotionally arousing for especially first-time parents as well. Maybe even more so than for the infant themselves (Swartz et al., 2016). An important factor that has been suggested to positively influence the transition to child care for parents is 'feeling good about leaving the child with the professional caregiver' (Swartz et al., 2016). In an effort to improve the confidence of the parent in the professional caregiver (i.e. to lower their level of parental separation anxiety in the context of child care), the VIPP-TICC involves the parent in the first visit to discuss child characteristics, caregiving practices and routines at home with the professional caregiver. Another goal of this visit was to stimulate the formation of a relationship between the professional caregiver and parent, which might lead to increased levels of the quality of care toward the parent provided by the professional caregiver, as perceived by the parent. Additionally, information on the infants' experiences at home can help the professional caregiver to attune caregiving practices to the infant at the $\mathrm{CCC}$, which may help to ease the transition for the infant as well.

About ten months after the first inclusion, we had to stop data collection due to the outbreak of the severe acute respiratory syndrome coronavirus-2 (SARS-CoV-2) and subsequent closure of CCC's in the Netherlands in March 2020. The limited number of participants who completed the intervention did not allow us to investigate the effectiveness of VIPP-TICC. However, the acquired data do provide valuable information about the feasibility of this intervention. In the current study we therefore examined how participants evaluated the content, practical aspects, and impact of the intervention, as well as the alliance 
with the intervener, since previous studies showed that a stronger alliance is associated with positive treatment outcomes (Baier et al., 2020). Additionally, we present (pre- and) posttreatment mean scores for most of the main outcome variables in the intervention and the control group, to investigate if there are any indications for efficacy of the intervention. Unfortunately, we were unable to include data on infants' cortisol levels in the current study, due to the high number of missing data.

\section{Research Questions}

1) How did professional caregivers and parents evaluate the intervention?

1a) How did professional caregivers and parents evaluate the content of the intervention?

1b) How did professional caregivers evaluate the practical aspects of the intervention?

1c) How did professional caregivers and parents evaluate the impact of the intervention on themselves, the infant, other children in the group (professional caregivers only), and future infants starting at the CCC (professional caregiver only)?

1d) How did professional caregivers and parents evaluate the strength of the alliance with the intervener?

2) Are there any indications for potential intervention effects on professional caregivers' sensitivity, the quality of child care as perceived by the parent, infants' well-being and securebase behavior, and parental separation anxiety?

\section{Method}

\section{Procedure}

Recruitment of professionals, parents and infants took place via child care organizations (CCO's) in several municipalities in the western region of the Netherlands. Organizations that were interested in participating in the study were sent an information brochure and contacted to further explain the study and to answer any questions. CCO's that 
agreed to participate were asked to make an overview of infants starting child care before they were 6 months old, for at least one day a week. We asked organizations to only include infants of parents who were able to communicate in Dutch and to exclude twins. Next, we contacted the future mentor of the first infant starting at the CCC (i.e. the professional caregiver who monitors the child's development and serves as the contact person for parents) to inform them about the study, and if they were interested, we sent them the information brochure. If the professional caregiver agreed to participate, someone within the organization contacted the parents of the selected infant to ask if they would be open to receiving information about our study. Interested families were sent the information brochure as well as an invitation letter describing the in- and exclusion criteria of our study. About one week later, the family was contacted by telephone. Families were excluded if the infant was born premature $(<37$ weeks), weighed less than 2500 grams at birth, had been hospitalized for 7 days or more in a row, used medication or had a condition or disorder that could influence one of the infant outcome measures.

After parental consent we scheduled a home visit (T0, not included in the current study), about 2 weeks before the start of the infant at the CCC and a pre-test visit (T1), which ideally took place on the first full day of the infant at the CCC (range = first - fourth day). After the pre-test visit, each triad (consisting of an infant, a professional caregiver and the parent of the infant) was randomly assigned to either the intervention or control condition. Both the VIPP-TICC and dummy intervention consisted of six bi-weekly contact moments starting about 2 weeks after the pre-test visit. The post-test visit (T2) was scheduled about 18 weeks after the pre-test visit $(M=17.90, S D=1.37$, range $=15-20$ weeks $)$, i.e. 1 to 6 weeks after the end of the (dummy) intervention. By the time of the post-test visit, one professional caregiver dropped-out (see Table 1). Therefore, this visit was completed by only 10 triads. After the pre- and post-test visit, professional caregivers and parents were asked to fill out a 
questionnaire. Lastly, a follow-up measurement (T3) was administered, 12 to 16 months after the pre-test visit $(M=13.50, S D=1.41)$, consisting of an online questionnaire for the professional caregiver only. The questionnaire was sent to eight of the professional caregivers (due to drop-out of two more triads, see Table 2) in November 2020, about 6 months after the reopening of CCC's following the first national lockdown because of SARS-CoV-2.

Informed consent was provided by both parents before the home visit and by the professional caregiver, her colleagues and the parents of the other children in the group of the participating infant before the pre-test visit. To promote participant retention, caregivers in the intervention condition received a small present at the end of the last visit of the intervention and all professional caregivers received $€ 40$,- at the end of the study. Parents received a small present for their child at the end of the home visit and €25,- at the end of the study. In addition, participants will be informed about the study results. The study was conducted in accordance with the ethical standards of the American Psychological Association and approved by the Ethics Committee of the Institute of Education and Child Studies of Leiden University (file number: ECPW-2018/220).

\section{Participants}

In total, 11 infants, professional caregivers and parents were included in the current study. See Table 1 for a detailed overview of some socio-demographic information, the condition, and missing data per triad. Part of the background information below is based on 10 families, because one parent did not fill out the pre-test questionnaire. All infants were firstborn children ( $55 \%$ boys). At the time of the pre-test, infants were on average 3.45 months old $(S D=1.13$, range $=2-6$ months $)$. The mean number of child care hours per week was $22.10(S D=10.16$, range $=8-40$ hours, $n=10)$. All parents were the biological mother of the infant, living together with the biological father of the infant. At the start of the study mothers were on average 31.60 years old $(S D=3.95$, range $=25$ - 38 years, $n=10)$; four of 
them completed higher vocational education and six of them had a university degree. The professional caregivers were all female, and on average 35.27 years old $(S D=11.32$, range $=$ 21 - 57 years). Nine of them completed intermediate vocational education and two professional caregivers completed higher vocational education. Moreover, five of the professional caregivers received an additional training on working with infants. The professional caregivers were on average working in child care for 11.14 years $(S D=7.86$, range $=8$ months -27 years $)$ of which 7.76 years $(S D=5.61$, range $=8$ months -18 years $)$ with infants.

\section{Intervention}

Triads allocated to the intervention condition $(n=4)$ received the VIPP-TICC. To develop the VIPP-TICC protocol, we revised the VIPP-SD manual (Juffer et al., 2016) using scientific literature on stress regulation in infants and information from the VIPP-CC. Additionally, we added an innovative element to the first visit, as we invited the parent to come to the CCC to discuss a video recording of the parent-child interaction at home together with the professional caregiver and the intervener. The video recording that was used was made during the home visit and showed how the parent prepared the child for a nap, including a diaper change, and put the child to sleep. After the discussion of the recording, some semistructured questions were discussed about characteristics of the child, e.g. what they like and dislike, what works for them in specific caregiving situations, and what routines are used in the care for the infant at home.

The other visits only included the professional caregiver and intervener, and as in VIPP-SD, these visits started with filming caregiver-child interactions in one to four daily situations, followed by a discussion of the recordings of the previous visit. Although for caregivers of 6- to 12-month old infants, VIPP without the Sensitive Discipline (SD) components is advised, we hypothesized that part of the SD techniques could also be relevant 
to sensitivity to distress, an aspect of sensitive caregiving that is thought to be crucial for the development of stress regulation, social-emotional well-being, and attachment security (Laurent et al., 2016; Leerkes et al., 2012). Therefore, we decided to replace the discipline situations by situations that might be (mildly) stressful to infants and used these situations to inform professional caregivers on the importance of the use of distraction as well as explaining to the child what is going to happen (both SD techniques) and establishing routines in order to prevent infant distress. Potential stressful situations included the handover process from the parent to the professional caregiver in the morning, being undressed and put to sleep, a diaper change, and waiting to be bottle-fed. Furthermore, these situations provided a basis to discuss comforting methods to sooth infants (which includes the SD technique showing understanding for the child, i.e. empathy) and to give tips on how to create and use opportunities for one-on-one interactions with an infant within the group setting. For an overview of the VIPP-TICC visits and the themes per visit, see Table 2. We decided to include only one booster session instead of two because of the pre-existing knowledge of our target population and potential benefit for the implementation of the intervention (i.e., less time consuming).

In order to pilot the intervention, $\mathrm{CV}$, who is a certified VIPP-SD intervener, supervisor, and trainer, trained two VIPP-SD interveners in the TICC module. The three of them piloted the VIPP-TICC in three triads. Following this pilot some last changes to the manual describing the structure, themes, tips, and exercises for caregivers and infants for each session were made (Vrijhof et al., 2019). Then, two master students were extensively trained by $\mathrm{CV}$, before implementing the intervention in the current study.

\section{Dummy Intervention}

To make sure the number of contact moments was the same for all participants, professional caregivers allocated to the control condition $(n=7)$ received a dummy 
intervention consisting of six phone calls. Parents $(n=7)$ received one phone call. As opposed to the intervention condition, no contact between the professional caregiver and parent was initiated by us in the control condition. During the phone call(s) a short semi-structured interview was conducted, inviting the professional caregiver or parent to talk about topics regarding the general development of the infant and the transition to child care. The interview was based on the interview Van Zeijl et al. (2006) used and that was thereafter used in various other RCT's testing the VIPP method (Juffer et al., 2017). No specific information or advice about child development, the transition to child care or caregiving was given to the participants in the control condition. If a participant had a question about one of these topics, they were given a short, general answer based on information that can be found on the website 'www.opvoeden.nl'. The dummy intervention was conducted by four students (including the students who delivered the VIPP-TICC).

\section{Measures}

\section{Evaluation of the VIPP-TICC and Alliance with the Intervener}

Following the post-test visit, both the professional caregiver and the parent were asked to fill out a detailed evaluation of the content and impact of the VIPP-TICC and of the alliance with the intervener. Furthermore, the professional caregiver reported on the practical aspects of the intervention. The evaluation filled out by the parent focused on the first visit. Professional caregivers evaluated both this first visit and the five visits including individual video-feedback sessions. We used closed and open-ended items. Closed items were mostly statements that could be answered on a 6-point scale $(1=$ strongly disagree / not useful at all 6 = strongly agree / very useful). An example of a 'content' item is: 'The discussion of the recording of the parent and infant at home with the parent was useful'. One item ('Which grade would you give the content of the intervention?') was answered on a 10-point scale, which corresponds to the grading system used in Dutch schools $(1=$ lowest $-10=$ highest $)$. 
The impact of the intervention was assessed for the professional caregiver, parent, target infant, other children in the group, and future infants starting child care in the group of the professional caregiver. An example of an 'impact' item is: 'I feel that I have learned something from the video training'. One impact item filled out by professional caregivers was answered on a 4-point scale: 'I applied the tips and advice that I received' $(1=$ not at all - $4=$ often). Furthermore, professional caregivers were asked to evaluate the practical aspects of the intervention: e.g. 'The discussion of the recordings could be implemented in my work'. Two items with regard to the practical aspects were answered on a 3-point scale: 'What did you think of the number / duration of the visits?' $(1=$ too little / too short, $2=$ good, $3=$ too many / too long). Finally, the strength of the alliance between the intervener and the professional caregiver and between the intervener and the parent was assessed with respectively 14 and 11 items, based on the revised Helping Alliance questionnaire (Luborsky et al., 1996). Two items were reverse coded so that higher scores on all items indicated a stronger, more positive alliance. Then, an overall mean score was computed. Additionally, we asked professional caregivers and parents which grade $(0-10)$ they would give the intervener. The open-ended questions in the questionnaire provided information on aspects of the intervention that were most useful to the participants and suggestions for improvement with regard to the content and implementation of the intervention. Data were missing for one parent (see Table 1).

\section{Caregiver Sensitivity}

Caregiver sensitivity towards the infant was observed in different one-on-one situations within the group setting. During both the pre- and post-test visit, professional caregivers were asked to play with the infant as they would normally do, with a standard set of toys for 8 minutes (play situation). Furthermore, we recorded the interaction when the professional caregiver got the infant ready for a nap, which included a diaper change, and put 
the infant to sleep as well as dressed the child after awakening (caregiving situation). All video recordings were coded using the 9-point Ainsworth Scales 'Sensitivity versus Insensitivity' and 'Cooperation versus Interference' with higher scores indicating higher levels of sensitivity and cooperation (Ainsworth et al., 1974). A total of four coders were trained by B. Because not all coders were reliable on both scales, and the coders were involved in the data collection, we decided to make a duo for each of the scales and have the duos double code all videos. All coders were blind to the treatment condition. The intraclass correlation coefficient (ICC) for the reliability set ranged from .68 - .82 for the convergence with the expert coder and was .55 for the duo coding sensitivity and .71 for the duo coding cooperation. During the coding of the data, the duo partners regularly met and compared scores. Whenever the scores differed 2 scale points or more (which occurred only a few times), the coders discussed the video and worked out a consensus score. If the scores differed only 1 scale point, the two scores were averaged.

The play and caregiving situations were analyzed separately, because the play situation might indicate sensitivity to non-distress whereas the caregiving situation may reflect sensitivity to distress (Leerkes et al., 2012). Because of low correlations between the subscales sensitivity and cooperation within the play and caregiving situation $(r=.38$ and $r=$ .13 respectively, based on the complete pre-test sample of $n=28$ ), we also analyzed the two subscales separately. Post-test data were completely missing for two professional caregivers. Furthermore, in one case only the play situation was observed, see Table 1.

\section{Quality of Child Care as Perceived by the Parent}

Perceived quality of child care was measured using the Emlen Scales (Emlen, 2000) after the post-test visit. We selected the subscales 'caregiver's warmth and interest in my child' (CWI; 6 items, e.g. 'The professional caregiver is warm and affectionate towards my child'), 'caregiver's skill' (CS; 3 items, e.g. 'The professional caregiver knows a lot about 
children and their needs') and 'supportive parent-caregiver relationship' (SPCR; 6 items, e.g. 'I feel welcomed by the professional caregiver'). The items were translated in Dutch and then back-translated for verification by a native speaker who is also fluent in Dutch. All 15 items were rated by the parent on a 5-point scale ranging from (1) never to (5) always. The internal consistency of the selected subscales proved to be good $(\alpha$ 's $>.80)$ in a Dutch sample of 619 parents with a child under the age of 4 years attending a CCC (De Vet et al., 2021b). The study by De Vet et al. (2021b) furthermore showed that the three subscales were highly correlated ( $r$ 's between .68 and .70). Because the CWI and CS subscales both focus on the professional caregivers' interactions with the infant, we decided to combine these scales and compute an overall mean score for perceived quality of care towards the infant. We also computed a mean score for the SPCR subscale reflecting the perceived quality of care towards the parent. Higher mean scores indicated higher quality of care as perceived by the parent. Data were missing for three professional caregivers, see Table 1.

\section{Infant Well-being}

Well-being of the infant was observed during both the pre- and post-test visit during three unstructured 2-minute episodes that were recorded at the start and end of the visit and once in between. Recordings were made regardless of whom the infant was with and what the infant was doing, but at least 30 minutes apart. After a training by $\mathrm{HV}$, the recordings were coded in pairs by $\mathrm{CV}, \mathrm{SdV}$, and $\mathrm{HV}$, because $\mathrm{CV}$ and $\mathrm{SdV}$ were not blind to the treatment condition of the triads after randomization. We used the Laevers Well-being Scale (Laevers, 2003), which was adapted and validated by the Dutch Consortium for Child Care Research for infants and toddlers in childcare (NCKO; De Kruijf et al., 2007). The scale contains several indicators of a child's well-being, such as pleasure, vitality, and relaxation and ranges from

(1) a very low well-being (signals of discomfort are clearly present, e.g., crying, screaming) to

(7) a very high well-being (signals of comfort are clearly present, e.g., enjoyment, smiling). 
The ICC with the expert coder (HV) was .75 for both CV and SdV, and .88 amongst CV and SdV. Because most training videos of Laevers (2003) as well as the reliability videos of the NCKO focused on toddlers, some videos made during pilot visits for the current study were discussed with HvB (an Infant Mental Health specialist). Following this discussion, information on (subtle) signals displayed by infants regarding for example pleasure (e.g. crowing), non-vitality (e.g. gazing, grabbing their ears) and distress (arching of the back, sucking on hand/finger) was added to the manual. Because infants are less capable than older children of showing their enthusiasm, we decided to give somewhat more weight to (subtle) signs of pleasure in the well-being score for (young) infants. Differences in the well-being score between coders were discussed until a consensus score was agreed upon. In some cases, the third coder was asked to score the video as well. We decided to treat the scores based on bottle-feeding episodes (maximally one episode per infant) as missing because we were unable to observe the full range of well-being scores in those episodes (maximum score of 4). Since well-being seemed to fluctuate during the day ( $r$ 's between .05 and .24 across the two to three episodes from the pre-test for the total sample of 28 infants), scores across the episodes were aggregated to give an impression of the overall level of well-being during the day, with higher mean scores indicating higher levels of well-being. Post-test data were completely missing for one infant, see Table 1.

\section{Attachment Security of the Infant as Perceived by the Professional Caregiver}

A questionnaire containing 61 items based on the self-report Attachment Q-Set (Version 3.0; Waters \& Deane, 1985) composed by Gartstein and Iverson (2014) and previously used in a Dutch sample by Hall et al. (2021), was adapted to measure the degree of attachment security of the infant to the professional caregiver by replacing the words 'my child' by the name of the child. The items describe (secure-base) behavior of young children during periods of interaction with the professional caregiver at the CCC (e.g. "(Name child) 
stops crying and quickly recovers when I hold him/her in my arms if (name child) is

frightened or upset"). Professional caregivers were instructed to fill out how characteristic the behavior was for the infant, ranging from (1) very uncharacteristic to (7) very characteristic of the infant. Thirty items were reverse coded (as described by Gartstein \& Iverson, 2014) after which we computed a mean score. A higher score reflected a higher level of secure base behavior indicating a higher level of attachment security as perceived by the professional caregiver. Data were missing for three infants, see Table 1.

\section{Parental Separation Anxiety}

The Maternal Separation Anxiety (MSA) subscale of the Maternal Separation Anxiety Scale (MSAS; Hock et al., 1989) was used to measure the level of separation anxiety of the parent after the pre-test and the post-test visit. The MSA subscale consists of 21 items focusing on the level of discomfort, sadness or guilt mothers feel associated with being separated from their infant. The items were adapted to fit the use in both mothers and fathers and to measure separation anxiety only related to the moments the child is at the CCC by changing phrases like 'when I am away from my child' into 'when my child is at the child care center' and 'than a babysitter or teacher' into 'than professional caregivers'. Following this step, we translated the items into Dutch and had them back-translated for verification by a native speaker. Parents were asked to rate their level of agreement with the statements on a 5point scale ranging from (1) strongly disagree to (5) strongly agree. Previous studies showed high levels of internal consistency: Cronbach's alpha for the MSA subscale varied from .87 .91 (De Vet et al., 2021b; Hock et al., 1989). A mean score was computed with higher scores indicating higher levels of parental separation anxiety. For one parent both the pre-test and post-test data were missing (control condition). For two other parents, only the post-test data were missing, see Table 1.

\section{Results}


Overall, the intervention and the alliance with the intervener were positively evaluated by three professional caregivers, whereas one professional caregiver was somewhat less positive. The same holds for the parents: one of the three parents was somewhat less positive. The professional caregiver and parent who were less positive were part of the same triad.

\section{Evaluation of the Content of the Intervention}

With regard to the first visit, all parents (strongly) agreed with the statement that the recording reflected typical interactions between themselves and their infant. Both professional caregivers and parents indicated that the discussion of the recording was useful: the mean score was 4.75 (range $=4-6$ ) for professional caregivers, and 4.67 (range $=4-5$, see Table 3) for parents. Moreover, parents evaluated the discussion of the recording as (somewhat) informative, clear, and interesting. One parent found the discussion confronting, and one parent thought the session was somewhat unnecessary, whereas the others (strongly) disagreed with the statements 'confronting' and 'unnecessary', see Table 3 . The usefulness of the discussion of the semi-structured questions was rated as 'somewhat useful' $(M=4.25$, range $=4-5)$ by professional caregivers and 'useful' $(M=5.33$, range $=5-6)$ by parents. Overall, parents rated the content of the first session a 7.00 (range $=6-8)$ on a 10-point scale. Parents reported that 'to see how you yourself do things', 'sharing information on how we raise our child and do things at home', and 'insights into how my child is cared for at the child care center' were most valuable. One of the parents indicated that she would like to 'learn more about the theory'. Other than that, no suggestions for improvement were given regarding the content of the first session.

All professional caregivers (strongly) agreed with the statement that the recordings reflected typical interactions between themselves and the infant. In general, professional caregivers indicated that the individual video-feedback sessions were informative, clear, interesting, and useful. Furthermore, all professional caregivers disagreed (strongly) when 
they were asked if the sessions were unnecessary. One professional caregiver found the discussion confronting, the others did not (see Table 4). Furthermore, we asked them how useful they found the discussion of the different situations that we recorded. Although individual ratings varied from 'somewhat useful' to 'very useful', all situations were mainly rated as useful. There were no clear indications that some of the recorded situations were more useful than others. We also asked the professional caregivers to rate the usefulness of the specific topics we talked about and gave advice on. Again individual scores ranged from 'somewhat useful' to 'very useful', but most subjects were rated as 'useful' by the majority of professional caregivers. All participants indicated that the information brochure that was given to them at the end of the intervention was useful. Overall, professional caregivers rated the content of the intervention a 7.75 (range $=6-9$ ) on a 10-point scale. When we asked what was most valuable to them, one of the professional caregivers answered 'seeing things you did not notice at the time' and one reported increased awareness of body language. There were no suggestions for improvement of the content of the intervention. However, one caregiver suggested to let the caregiver talk more and let them explain why they do something in a certain way.

\section{Evaluation of the Practical Aspects of the Intervention}

Three of the four professional caregivers indicated that the number and duration of the visits were 'good', whereas one professional caregiver indicated that there were 'too many' visits and that the duration of the visits was 'too long'. Most professionals indicated that the situations that had to be filmed could be implemented in their work (one 'somewhat agreed' and two 'agreed'). The same holds for the video-feedback sessions (three 'agreed'). One professional caregiver disagreed with both statements. Suggestions to improve the practical aspects of the intervention were 'shorter moments' and 'use of extra personnel, but this depends upon the manager'. 


\section{Evaluation of the Impact of the Intervention}

With regard to the impact of the first visit of the intervention involving the parent, only one professional caregiver indicated that what she heard or saw during that visit influenced how she cared for/interacted with the infant (score of 5, 'agree'). The parent of the infant however, disagreed when asked if the discussion of the recordings impacted how the professional caregiver cared for/interacted with the infant. With regard to the other professional caregivers, one 'somewhat disagreed' and two 'disagreed'. For one of the professional caregivers who disagreed, the parent thought that the discussion of the recording did have an impact on how the professional caregiver cared for/interacted with the infant to some extent, whereas the other parent 'disagreed' as well. Regarding the impact of the first visit on the infant, two out of the three parents reported that the visit had been (somewhat) beneficial to their child $(M=3.67$, range $=2-5)$. Furthermore, all parents stated that the visit had been (somewhat) beneficial to themselves $(M=5.00$, range $=4-6)$.

With regard to the intervention as a whole, professional caregivers were generally positive about the impact of their participation in the intervention, see Table 5. Half of the professional caregivers reported that it made them think about the care for infants in general and all the professional caregivers indicated that it made them think about how they can help infants with the transition from home to child care, at least to some extent. Furthermore, they all felt that they learned new things to some extent. Most professional caregivers reported that the target infant had (somewhat) benefited from their participation in the intervention and all of the professional caregivers reported that future infants starting child care at their group will benefit (somewhat) from their participation in the intervention. Moreover, half of the professional caregivers reported that their participation in the training had been beneficial to the other children in their group. Lastly, three out of the four professional caregivers indicated that they applied the tips and advice they received 'sometimes' and one caregiver 'often'. 


\section{Evaluation of the Alliance with the Intervener}

All of the professional caregivers and parents reported a positive alliance with the intervener. Scores ranged from 4.43 to 5.64 with a mean score of 4.96 for professional caregivers. The mean score for parents was 4.52 (range $=4.09-4.82)$. With regard to the grade, results showed that one duo (i.e. professional caregiver and parent) gave the intervener a 7, two duos graded the intervener an 8 and one professional caregiver gave the intervener a 9 (the parent of this duo did not fill out the questionnaire).

\section{Preliminary Outcomes}

An overview of the mean pre- and post-test scores for the professional caregiver, infant and parental outcomes for the intervention and control group can be found in Table 6 . Whenever data from a participant were missing on a specific outcome measure for either the pre-test or the post-test data, all data from that participant were disregarded when computing group mean scores for that specific outcome measure. No statistical tests were performed considering the small sample size, and therefore we do not know if differences that are described below are statistically significant.

Scores on sensitivity and cooperation for the professional caregivers in the intervention group generally decreased over time (difference scores ranged from -0.84 to 1.17), except for sensitivity in the caregiving situation, which slightly increased (difference score of 0.33 ). In the control group, sensitivity scores increased somewhat over time (difference score of 0.50 for play and 0.40 for caregiving), whereas cooperation scores decreased, especially in the caregiving situation (differences score of -1.10 , and -0.08 for play). Quality of care towards the infant was rated a little higher by parents in the intervention condition than parents in the control condition (difference score of 0.25 between the two groups at post-test), whereas there was virtually no difference in the quality of care towards parents between the two groups at post-test. Furthermore, we did not find an indication for a 
potential intervention effect on infant well-being: scores slightly increased from pre- to posttest in the intervention condition (difference score of 0.22 ), as well as in the control condition (difference score of 0.12). The level of secure base behavior was found to be a little higher in the control group than in the intervention group (difference score of 0.34 between the two groups at post-test). Finally, the descriptive statistics indicated that separation anxiety of the parents decreased over time in both conditions, with a somewhat greater decrease in the intervention condition (0.43) than in the control condition (0.21).

\section{Discussion}

The current feasibility study showed that the content, practical aspects and impact of the VIPP-TICC were overall positively evaluated by professional caregivers and parents. Furthermore, the strength of the alliance with the VIPP-TICC intervener was generally positively evaluated by both professional caregivers and parents. Despite these promising, positive evaluations, we did not find indications for the effectiveness of the VIPP-TICC in increasing sensitivity of the professional caregivers and promoting infant well-being and secure base behavior. With regard to the outcome measures related to parents, the descriptive statistics did show some small changes in favor of the intervention group: maternal separation anxiety decreased somewhat more over time and the perceived quality of care towards the infant was somewhat higher. It should be noted though that these differences were not statistically tested due to the small number of participants in the current study.

\section{Evaluation of the First Visit of the VIPP-TICC by Professional Caregivers and Parents}

Both professional caregivers and parents indicated that the discussion of the recording during the first visit was useful. The discussion of the semi-structured questions was thought to be useful as well, although it was evaluated a little less positive than the video-feedback part of the session by professional caregivers. Parents, however, were more positive about the 
discussion of the questions than the discussion of the recording. This could indicate that parents find it more helpful to talk about their child and their way of caregiving, whereas professional caregivers find it more useful to see how parents interact with their infant. Furthermore, that the results indicated that most professional caregivers and parents did not think that the first visit impacted the behavior of the professional caregiver in relation to the infant. At first sight this seems to be discrepant with the positive evaluation of the usefulness of the first visit. However, it could be that parents mostly rated the first visit as useful because of the positive impact the visit had on themselves and the infant rather than because of how the visit impacted the behavior of the professional caregiver. For professional caregivers it is less clear from the results of the current study what makes that they evaluated the first visit with the parent as useful. Speculatively, the first session might have contributed to them getting to know the child and parent better, which consequently might have promoted a partnership with the parent. Future research should investigate this more in depth. Lastly, it is important to note that no suggestions for improvement of the content of the first visit of the intervention were given by the parents.

\section{Evaluation of the VIPP-TICC by Professional Caregivers}

Professional caregivers endorsed the need for the intervention and generally evaluated the content positively, although one of the professional caregivers was somewhat less positive about the content of the intervention than the others. This professional caregiver furthermore indicated some practical issues: too many/long visits and issues with fitting the situations that needed to be recorded and the video-feedback sessions into her work. The other caregivers did not report issues with regard to the practical aspects of the intervention. Furthermore, most professional caregivers reported a positive impact on the infant, and all indicated that they had learned new things. Moreover, it made them all think about how to help infants make the transition from home to child care, which might explain why they expected a positive impact 
for future infants starting in child care in their group as well. The impact of the intervention on the care of infants in general and the benefits for other children in the group were less clear, which makes sense considering the aims of the intervention. The lower ratings by one of the professional caregivers might be partly explained by the relatively lower alliance score this professional caregiver reported, since previous studies showed that a stronger therapeutic alliance is related to more positive treatment outcomes and strength of the alliance can be identified as a mediator of change (Baier et al., 2020).

\section{Discussion of the Preliminary Outcomes}

The descriptive statistics showed that sensitivity and cooperation of the professional caregivers generally decreased over time in the intervention group, except for sensitivity in the caregiving situation, which slightly increased. This latter outcome measure is most likely to reflect sensitivity to distress and could therefore be considered the most important construct in light of the ultimate goal of the intervention: promoting infant stress-regulation, well-being and secure base behavior (Laurent et al., 2016; Leerkes et al., 2012). The small increase over time was however also found in the control group, as was the decrease in cooperation over time. Speculatively, a decrease in cooperation over time might be related to an increase in the level of physical activity infants display, which could make it more difficult for professional caregivers to refrain from interfering with the ongoing behavior of infants as they mature. The decrease in sensitivity in the play situation for the intervention group as opposed to the small increase for the control group is remarkable. This might be related to the relatively high levels of sensitivity during play at the time of the pre-test in the intervention group compared to the control group. One could argue that (highly) competent caregivers are less likely to profit from the intervention, or speculatively that the intervention may even be disadvantageous for such knowledgeable 'experts' (Kalyuga et al., 2003; Kolijn et al., 2021), whereas professional caregivers who are less sensitive at baseline are more likely to benefit from the intervention. 
As the sensitivity of the professional caregiver was hypothesized to be the mechanism underlying intervention effects on infant well-being and secure base behavior, it is not surprising that we did not find indications for intervention effects on infant outcomes either.

With regard to the secondary aim of the intervention, i.e. easing the transition for parents, we did find some first, small indications of the effectiveness of the intervention in the descriptive statistics: maternal separation anxiety seemed to decrease somewhat more over time in the intervention group and the perceived quality of care towards the infant seemed to be somewhat higher for this group. However, the quality of care towards the parent (as perceived by the parent) did not seem to differ between the intervention and control group. Easing the transition to child care for parents would possibly not only be beneficial to parents themselves, but could also positively influence the adjustment process of infants starting in child care, since emotional reactions of parents are likely to influence the emotional reactions of their children (Nelson et al., 2009), potentially via physiological processes (Waters et al., 2014) or parenting behavior (Cooklin et al., 2013; Deater-Deckard, 1998). Speculatively, parents with low levels of separation anxiety related to their child attending a CCC may be more relaxed during the drop-off and might give their child the idea that the $\mathrm{CCC}$ is a good place for them to be. Parents reporting higher levels of separation anxiety on the other hand might be more anxious and stressed during the drop-off and could give their child the idea that the CCC is inferior to the home environment or even an unsafe place. Children might pick up on their parents' stress and become stressed themselves. This idea is supported by the finding in one of our other studies (De Vet et al., 2021c) that anticipated maternal separation anxiety might be positively related to an increase in cortisol during the day at the CCC. In another study we found a relation with infant well-being shortly after the start in child care, but in the opposite direction than we expected: higher levels of seperation anxiey seemed to be related to higher levels of infant well-being (Vrijhof et al., 2021). More research in a larger 
sample is needed to investigate the relation between (anticipated) maternal separation anxiety and infant stress and well-being at child care.

\section{Limitations and Strengths}

The most important limitation of the current study is the small sample size. We were planning to set up an RCT with 50 professional caregivers in the intervention group and 50 professional caregivers in the control group. However, because of the outbreak of SARSCoV-2 the current study included only 4 participants in the intervention group and 7 in the control group. Moreover, data were incomplete in a number of cases leading to even smaller sample sizes for the preliminary outcomes. The small sample size precluded the performance of statistical tests, leaving us unable to investigate if differences between the intervention and control group were statistically significant. This should be taken into consideration when interpreting the results, which should be weighed really carefully, especially with regard to the preliminary outcomes. The inclusion of several outcome measures (including observations) and a control group to investigate potential indications of the effectiveness of the VIPP-TICC, next to a thorough evaluation of the intervention, are important strengths of the current study.

A second limitation of the current study is the potentially biased sample. Since the beginning of 2019, child care organizations have to adhere to an increased professional caregiver-infant ratio, while dealing with shortage of labor and more strict rules to assure the stability of care, which makes it hard for managers to relieve professional caregivers from their work duties and arrange a substitute caregiver to take over from them. The high workload for professional caregivers and these organizational difficulties complicated the recruitment for the current study and increased the likelihood that we included particularly well-organized organizations and highly motivated staff members, which is reflected in the 
high sensitivity scores of professional caregivers in the current sample. Results may thus not be representative for the total population of professional caregivers.

Despite these limitations, the current study is the first study that we know of aiming to ease the transition to child care for infants as well as their parents. Parents are often overlooked when studying emotional reactions related to the transition to child care, even though research suggests that the transition might be even more difficult for parents than for very young children (Swartz et al., 2016), and that the emotional reactions of parents to the transition might co-determine the emotional reactions of their children (Nelson et al., 2009; Waters et al., 2014).

\section{Research and Practical Implications}

In view of the generally positive evaluation of the intervention by professional caregivers and parents, the VIPP-TICC could be considered a good candidate intervention for testing in a large-scale RCT after adapting the intervention in such a way that it can be more easily implemented, preferably in consultation with professional caregivers, their managers, and pedagogical coaches. When testing the effectiveness of an adapted version of the intervention, one could consider training the pedagogical coaches working at CCC's (child care organizations in the Netherlands are obliged to appoint a pedagogical coach since 2019) in the intervention and have them implement the VIPP-TICC in their organization. These coaches could identify professional caregivers that are less sensitive and would probably benefit most from the intervention. One could also think about targeting professional caregivers of infants displaying high levels of negative emotionality since those infants seem to receive less sensitive care from professional caregivers (Albers et al., 2007), while these infants may be most susceptible to the quality of child care they receive. 
Considering the positive evaluation of the content of the first visit and (potential) impact on parents, investigating the effects of a single video-feedback session with both the parent and professional caregiver, might also be a promising direction for future research. Especially first-time parents and parents with higher levels of separation anxiety might benefit from such a session, as well as parents of children that might be at risk for a difficult transition to center-based child care, for example children with a more difficult temperament or children suffering from separation anxiety. Pedagogical coaches could be trained in making recordings and providing video-feedback to the parent and professional caregiver as well as the additional discussion of general questions. Such a session could probably rather easily be linked to the intake interview, which is commonly initiated by CCO's in the Netherlands just before the start of the infant in child care. Another option would be to give families instructions on how to make their own recordings, which might lead to even more naturalistic videos and minimizes the time a pedagogical coach would need to spend on preparing the session, thereby benefiting the feasibility of the session. A final option, which would be even easier to implement, could be to train professional caregivers in discussing the video materials with the parents themselves during the intake interview. By implementing this session even before the start we might be able to decrease maternal levels of anticipated separation anxiety, which in turn could affect infants' adjustment to child care (De Vet et al., 2021c; Vrijhof et al., 2021).

\section{Conclusion}

The VIPP-TICC intervention was positively evaluated by both professional caregivers and parents with regard to the content, practical aspects, and impact. The preliminary outcomes however, did not show indications of intervention effects on the professional caregivers or infants. Preliminary outcomes with regard to an effect of the intervention on parents were somewhat more positive. It should be noted though that the sample of the current 
study was very small and no statistical tests were performed to investigate potential differences between the intervention and control group. Taken together, the results of the current feasibility study indicate that especially the implementation of a video-feedback session and discussion with the professional caregiver and parent together might be an interesting direction for future research.

\section{Acknowledgements}

The authors would like to thank the child care organizations, professional caregivers, parents and children that participated in the study. Furthermore, we would like to thank the members of the focus group who helped us prepare for the RCT, the students who helped to recruit the participants, collected and coded the data, and our research assistant Jane Pieplenbosch. A special thanks goes to Sharon de Hingh and Myrthe de Wolf, who performed the intervention and dummy intervention for all of the cases included in the current study. Lastly we would like to thank Prof. dr. Femmie Juffer and Prof. dr. Marian Bakermans-Kranenburg for their feedback on the VIPP-TICC manual. This work was supported by a grant from the Netherlands Organization for Health Research and Development (grant number 544001004). The funding source was not involved in the preparation of the manuscript. C.I. Vrijhof and S.M. de Vet are joint first authors. The authors have no conflicts of interest to declare.

\section{Data availability statement}

Upon publication a publication package will be stored at https://dataverse.nl/. Data are available from the authors upon reasonable request which can be send to Dr. Harriet Vermeer: vermeer@fsw.leidenuniv.nl. 


\section{Reference list}

Ahnert, L., Gunnar, M. R., Lamb, M. E., \& Barthel, M. (2004). Transition to child care: Associations with infant-mother attachment, infant negative emotion, and cortisol elevations. Child Development, 75(3), 639-650. https://doi.org/10.1111/j.14678624.2004.00698.x

Ainsworth, M. D. S., Bell, S. M., \& Stayton, D. J. (1974). Infant-mother attachment and social development: Socialisation as a product of reciprocal responsiveness to signals. In M. P. M. Richards (Ed.), The introduction of the child into a social world (pp. 9135). Cambridge University Press.

Ainsworth, M. D. S., Blehar, M. C., Waters, E., \& Wall, S. (1978). Patterns of attachment: A psychological study of the strange situation. Lawrence Erlbaum Associates.

Albers, E. M., Beijers, R., Riksen-Walraven, J. M., Sweep, F. C. G. J., \& De Weerth, C. (2016). Cortisol levels of infants in center care across the first year of life: Links with quality of care and infant temperament. Stress: The International Journal on the Biology of Stress, 19(1), 8-17. https://doi.org/10.3109/10253890.2015.1089230

Albers, E. M., Riksen-Walraven, J. M., \& De Weerth, C. (2007). Infants' interactions with professional caregivers at 3 and 6 months of age: A longitudinal study. Infant Behavior \& Development, 30(4), 631-640. https://doi.org/10.1016/j.infbeh.2007.03.006

Badanes, L. S., Dmitrieva, J., \& Watamura, S. E. (2012). Understanding cortisol reactivity across the day at child care: The potential buffering role of secure attachments to caregivers. Early Childhood Research Quarterly, 27(1), 156-165.

https://doi.org/10.1016/j.ecresq.2011.05.005 
Baier, A. L., Kline, A. C., \& Feeny, N. C. (2020). Therapeutic alliance as a mediator of change: A systematic review and evaluation of research. Clinical Psychology Review, 82. https://doi.org/10.1016/j.cpr.2020.101921

Bernard, K., Peloso, E., Laurenceau, J. P., Zhang, Z. Y., \& Dozier, M. (2015). Examining change in cortisol patterns during the 10 -week transition to a new child-care setting. Child Development, 86(2), 456-471. https://doi.org/10.1111/cdev.12304

Cooklin, A. R., Giallo, R., D'Esposito, F., Crawford, S., \& Nicholson, J. M. (2013). Postpartum maternal separation anxiety, overprotective parenting, and children's social-emotional well-being: Longitudinal evidence from an Australian cohort. Journal of Family Psychology, 27(4), 618-628. https://doi.org/10.1037/a0033332

De Kruijf, R. E. L., Vermeer, H. J., Fukkink, R. G., Riksen-Walraven, J. M. A., Tavecchio, L. W. C., van IJzendoorn, M. H., \& van Zeijl, J. (2007). De nationale studie pedagogische kwaliteit kinderopvang: Eindrapport project 0 en 1 [The national study childcare quality: Final report project 0 and 1].

De Vet, S. M., Vrijhof, C. I., Van der Veek, S. M. C., Linting, M., \& Vermeer, H. J. (2021a). Young children's cortisol levels in out-of-home child care: A meta-analysis. Manuscript submitted for publication.

De Vet, S. M., Vrijhof, C. I., Van der Veek, S. M. C., Pieplenbosch, J. M., Van Bakel, H. J. A., \& Vermeer, H. J. (2021b). Child care in times of COVID-19: Predictors of distress in Dutch children and parents when re-entering centre-based child care after a 2-month lockdown. Frontiers in Psychology, 12:718898. https://doi.org/10.3389/fpsyg.2021.718898 
De Vet, S. M., Vrijhof, C. I., Van der Veek, S. M. C., Van Bakel, H. J. A., \& Vermeer, H. J. (2021c). Infants' diurnal cortisol during the transition to center-based child care: Exploring associations with maternal, child care and child characteristics. Manuscript submitted for publication.

Deater-Deckard, K. (1998). Parenting stress and child adjustment: Some old hypotheses and new questions. Clinical Psychology: Science and Practice, 5(3), 314-332. https://doi.org/10.1111/j.1468-2850.1998.tb00152.x

Dettling, A. C., Gunnar, M. R., \& Donzella, R. (1999). Cortisol levels of young children in full-day childcare centers: relations with age and temperament. Psychoneuroendocrinology, 24(5), 519-536. https://doi.org/10.1016/S03064530(99)00009-8

Eckstein-Madry, T., Piskernik, B., \& Ahnert, L. (2020). Attachment and stress regulation in socioeconomically disadvantaged children: Can public childcare compensate? Infant Mental Health Journal. https://doi.org/10.1002/imhj.21878

Emlen, A. C., Koren, P. E., \& Schultze, K. H. (2000). A packet of scales for measuring quality of child care from ap arent's point of view. Regional Research Insitute for Human Services, Portland state University. http://www.ssw.pdx.edu/focus/emlen/pgOregon.php

Essex, M. J., Klein, M. H., Cho, E., \& Kalin, N. H. (2002). Maternal stress beginning in infancy may sensitize children to later stress exposure: Effects on cortisol and behavior. Biological Psychiatry, 52(8), 776-784. https://doi.org/10.1016/s00063223(02)01553-6

Gartstein, M. A., \& Iverson, S. (2014). Attachment security: The role of infant, maternal, and contextual factors. International Journal of Psychology and Psychological Therapy, 14(2), 261-276. 
Gunnar, M. R., \& Cheatham, C. L. (2003). Brain and behavior interface: Stress and the developing brain. Infant Mental Health Journal, 24(3), 195-211. https://doi.org/10.1002/imhj.10052

Gunnar, M. R., \& Donzella, B. (2002). Social regulation of the cortisol levels in early human development. Psychoneuroendocrinology, 27(1-2), 199-220. https://doi.org/10.1016/S0306-4530(01)00045-2

Hall, R., Van Bakel, H., De Wolff, M., Klein Velderman, M., \& Alberti, J. (2021). The validity of a new checklist for disturbed child attachment. Manuscript submitted for publication.

Hock, E., Mcbride, S., \& Gnezda, M. T. (1989). Maternal separation anxiety: Mother-infant separation from the maternal perspective. Child Development, 60(4), 793-802. https://doi.org/10.2307/1131019

Howes, C., Galinsky, E., \& Kontos S. (1998). Child care caregiver sensitivity and attachment. Social Development, 7(1), 25-36. https://doi.org/10.1111/1467-9507.00048.

Juffer, F., Bakermans-Kranenburg, M. J., \& Van IJzendoorn, M. H. (2008). Promoting positive parenting: An attachment-based intervention. Lawrence Erlbaum.

Juffer, F., Bakermans-Kranenburg, M. J., \& Van IJzendoorn, M. H. (2016). Handleiding VIPP-SD: Video-feedback Intervention to promote Positive Parenting and Sensitive Discipline (3.0 ed.). Leiden University.

Juffer, F., Bakermans-Kranenburg, M. J., \& Van IJzendoorn, M. H. (2017). Video-feedback Intervention to promote Positive Parenting and Sensitive Discipline (VIPP-SD): Development and meta-analytic evidence of its effectiveness. In H. Steele \& M. Steele (Eds.), Handbook of Attachment-Based Interventions. Guilford Press.

Kalyuga, S., Ayres, P., Chandler, P., \& Sweller, J. (2003). The expertise reversal effect. Educational Psychologist, 38(1), 23-31. https://doi.org/10.1207/S15326985ep3801_4 
Kolijn, L., Van den Bulk, B. G., Van IJzendoorn, M. H., Bakermans-Kranenburg, M. J., \& Huffmeijer, R. (2021). Does maternal inhibitory control mediate effects of a parenting intervention on maternal sensitive discipline? Evidence from a randomized-controlled trial. Manuscript submitted for publication.

Kopp, C. B. (1989). Regulation of distress and negative emotions: A developmental view. Developmental Psychology, 25(3), 343-354. https://doi.org/10.1037/00121649.25.3.343

Laevers, F., Aerden, I., De Bruyckere, G.,Moons, J. \& Silkens, K. (2003). Belevingsonderzoek bij het jonge kind in opvangsituaties buiten huis. Eindrapport. Leuven: Expertisecentrum Ervaringsgericht Onderzoek.

Laurent, H. K., Harold, G. T., Leve, L., Shelton, K. H., \& Van Goozen, S. H. M. (2016). Understanding the unfolding of stress regulation in infants. Development and Psychopathology, 28(4), 1431-1440. https://doi.org/10.1017/S0954579416000171

Leerkes, E. M., Weaver, J. M., \& O'Brien, M. (2012). Differentiating maternal sensitivity to infant distress and non-distress. Parenting: Science and Practice, 12(2-3), 175-184. https://doi.org/10.1080/15295192.2012.683353

Luborsky, L., Barber, J. P., Siqueland, L., Johnson, S., Najavits, L. M., Frank, A., \& Daley, D. (1996). The revised Helping Alliance questionnaire (HAq-II): Psychometric properties. Journal of Psychotherapy Practice and Research, 5(3), 260-271.

Murray, D. W., Rosanbalm, K. D., Christopoulos, C., \& Hamoudi, A. (2015). Self-regulation and toxic stress report 1: Foundations for understanding self-regulation from an applied perspective. Retrieved from: https://www.acf.hhs.gov/opre/report/selfregulation-and-toxic-stress-foundations-understanding-self-regulation-applied 
Nelson, J. A., O'Brien, M., Blankson, A. N., Calkins, S. D., \& Keane, S. P. (2009). Family stress and parental responses to children's negative emotions: Tests of the spillover, crossover, and compensatory hypotheses. Journal of Family Psychology, 23(5), 671679. https://doi.org/10.1037/a0015977

Swartz, R. A., Speirs, K. E., Encinger, A. J., \& McElwain, N. L. (2016). A mixed methods investigation of maternal perspectives on transition experiences in early care and education. Early Education and Development, 27(2), 170-189. https://doi.org/10.1080/10409289.2016.1087777

Tryphonopoulos, P. D., Letourneau, N., \& Azar, R. (2014). Approaches to salivary cortisol collection and analysis in infants. Biological Research for Nursing, 16(4), 398-408. https://doi.org/10.1177/1099800413507128

Van Zeijl, J., Mesman, J., Van IJzendoorn. M. H., Bakermans-Kranenburg, M. J., Juffer, F., Stolk, M. N., Koot, H. M., \& Alink, L. R. (2006). Attachment-based intervention for enhancing sensitive discipline in mothers of 1- to 3-year-old children at risk for externalizing behavior problems: A randomized controlled trial. Journal of Consulting and Clinical Psychology, 74(6), 994-1005. https://doi.org/10.1037/0022006X.74.6.994

Vermeer, H. J., \& Groeneveld, M. G. (2017). Children's physiological responses to childcare. Current Opinion in Psychology, 15, 201-206. https://doi.org/10.1016/j.copsyc.2017.03.006

Vrijhof, C. I., De Vet, S. M., Vermeer, H. J., \& Van der Veek, S. M. C. (2019). Handleiding VIPP-TICC: Video-feedback Intervention to promote Positive Parenting - Transition to Infant Child Care. Leiden University. 
Vrijhof, C. I., De Vet, S. M., Van der Veek, S. M. C., Van Bakel, H. J. A., \& Vermeer, H. J. (2022). Exploring the relation between maternal separation anxiety and infant wellbeing after the start in center-based child care. Manuscript in preparation.

Waters, E., \& Deane, K. E. (1985). Defining and assessing individual differences in attachment relationships: Q-methodology and the organization of behavior in infancy and early childhood. Monographs of the Society for Research in Child Development, 50(1-2), 41-65. https://doi.org/https://doi.org/10.2307/3333826

Waters, S. F., West, T. V., \& Mendes, W. B. (2014). Stress Contagion Physiological Covariation Between Mothers and Infants. Psychological Science, 25(4), 934-942. https://doi.org/10.1177/0956797613518352

Werner, C. D., Vermeer, H. J., Linting, M., \& Van IJzendoorn, M. H. (2018). Video-feedback intervention in center-based child care: A randomized controlled trial. Early Childhood Research Quarterly, 42, 93-104. https://doi.org/10.1016/j.ecresq.2017.07.005 


\section{Table 1}

Socio-Demographic Information and Overview of Missing Data per Triad $(n=11)$

\begin{tabular}{|c|c|c|c|c|c|c|c|c|c|}
\hline Triad & $\begin{array}{l}\text { Infant } \\
\text { gender }\end{array}$ & $\begin{array}{l}\text { Infant age } \\
\text { in months }\end{array}$ & $\begin{array}{l}\text { No hours } \\
\text { in child } \\
\text { care }\end{array}$ & $\begin{array}{l}\text { Parent } \\
\text { age in } \\
\text { years }\end{array}$ & $\begin{array}{l}\mathrm{PC} \\
\text { age in } \\
\text { years }\end{array}$ & $\begin{array}{l}\text { PC work } \\
\text { experience } \\
\text { in years }\end{array}$ & $\begin{array}{l}\mathrm{PC} \\
\text { additional } \\
\text { infant } \\
\text { training }\end{array}$ & Condition & Missing data \\
\hline A & Girl & 3 & 30 & 33 & 37 & 15.00 & No & Intervention & \\
\hline B & Boy & 3 & & & 21 & .67 & No & Control & $\begin{array}{l}\text { Parent did not fill out the questionnaires; } \\
\text { no T2 sensitivity data available and T3 not possible: } \\
\text { PC employment termination just before T2 }\end{array}$ \\
\hline $\mathrm{C}$ & Girl & 3 & 12 & 38 & 30 & 9.00 & No & Control & \\
\hline $\mathrm{D}$ & Girl & 5 & 20 & 28 & 40 & 21.08 & Yes & Intervention & T3 not possible: child had switched groups \\
\hline $\mathrm{E}$ & Boy & 4 & 24 & 31 & 30 & 7.42 & No & Control & \\
\hline $\mathrm{F}$ & Boy & 6 & 10 & 33 & 53 & 27.00 & Yes & Control & \\
\hline G & Boy & 3 & 8 & 29 & 36 & 12.50 & Yes & Intervention & \\
\hline $\mathrm{H}$ & Boy & 3 & 20 & 37 & 57 & 11.83 & No & Control & \\
\hline I & Girl & 3 & 30 & 32 & 28 & 1.83 & No & Control & $\begin{array}{l}\text { Only evaluation of the intervention available: } \\
\text { Parent partly filled out } \mathrm{T} 2 \text { questionnaire }\end{array}$ \\
\hline $\mathrm{J}$ & Girl & 2 & 40 & 25 & 33 & 11.00 & Yes & Intervention & $\begin{array}{l}\text { T2 visit not possible due to illness PC; } \\
\text { Parent did not fill out T2 questionnaire }\end{array}$ \\
\hline K & Boy & 3 & 27 & 30 & 23 & 5.17 & Yes & Control & $\begin{array}{l}\text { T2 adjusted visit due to injury PC: } \\
\text { sensitivity in caregiving situation missing; } \\
\text { T3 not possible: family emigrated after T2 }\end{array}$ \\
\hline
\end{tabular}

Note. $P C=$ professional caregiver $; T 2=$ post-test $; T 3=$ follow-up 
Table 2

Overview of the Visits and Accompanying VIPP and TICC Themes

\begin{tabular}{|c|c|c|}
\hline & VIPP theme & TICC theme \\
\hline Visit 1 & & $\begin{array}{l}\text { Getting to know the child and their } \\
\text { experiences at home }\end{array}$ \\
\hline Visit 2 & Exploration vs. attachment behavior & Getting used to a new environment \\
\hline Visit 3 & Speaking for the child & $\begin{array}{l}\text { Providing individual attention to } \\
\text { infants within a group setting }\end{array}$ \\
\hline Visit 4 & Sensitivity chain & $\begin{array}{l}\text { Importance of distraction, giving } \\
\text { notice and establishing routines }\end{array}$ \\
\hline Visit 5 & Sharing emotions & Comforting techniques \\
\hline Visit 6 & Booster session (no new theme) & Booster session (no new theme) \\
\hline
\end{tabular}


Table 3

Evaluation of the Content of the Discussion of the Recording of the Parent-Infant Interaction at Home during the First Visit by Parents $(n=3$; Means and Number of Parents per Category).

\begin{tabular}{lccccccc}
\hline & Mean & $\begin{array}{c}\text { Strongly } \\
\text { disagree }\end{array}$ & Disagree & $\begin{array}{c}\text { Somewhat } \\
\text { disagree }\end{array}$ & $\begin{array}{c}\text { Somewhat } \\
\text { agree }\end{array}$ & $\begin{array}{c}\text { Agree } \\
\text { Strongly } \\
\text { agree }\end{array}$ \\
\hline Unnecessary & 2.00 & 2 & & & 1 & & \\
Informative & 4.67 & & & & 2 & & 1 \\
Clear & 4.67 & & & & 1 & 2 & \\
Confronting & 3.00 & 1 & 1 & & & & 1 \\
Interesting & 5.67 & & & & 1 & 2 \\
Useful & 4.67 & & & & & 1 & 2 \\
\hline
\end{tabular}




\section{Table 4}

Evaluation of the Content of the Individual Video-Feedback Sessions by Professional Caregivers ( $n=4$; Means and Number of Professional Caregivers per Category).

\begin{tabular}{lccccccc}
\hline & Mean & $\begin{array}{c}\text { Strongly } \\
\text { disagree }\end{array}$ & Disagree & $\begin{array}{c}\text { Somewhat } \\
\text { disagree }\end{array}$ & $\begin{array}{c}\text { Somewhat } \\
\text { agree }\end{array}$ & $\begin{array}{c}\text { Agree } \\
\text { Strongly } \\
\text { agree }\end{array}$ \\
\hline Unnecessary & 1.50 & 2 & 2 & & & & \\
Informative & 4.25 & & 1 & & & 3 & \\
Clear & 5.00 & & & & 1 & 4 & \\
Confronting & 2.25 & 1 & 2 & & 1 & 2 & 1 \\
Interesting & 5.00 & & & & 1 & 2 & 1 \\
Useful & 5.00 & & & & 1 & \\
\hline
\end{tabular}




\section{Table 5}

Evaluation of the Impact of the Intervention as a Whole as Reported by Professional Caregivers $(n=4)$ on Themselves, the Infant, Other

Children and Future Infants (Means and Number of Professional Caregivers per Category).

\begin{tabular}{|c|c|c|c|c|c|c|c|}
\hline The video training & Mean & $\begin{array}{l}\text { Strongly } \\
\text { disagree }\end{array}$ & Disagree & $\begin{array}{c}\text { Somewhat } \\
\text { disagree }\end{array}$ & $\begin{array}{l}\text { Somewhat } \\
\text { agree }\end{array}$ & Agree & $\begin{array}{c}\text { Strongly } \\
\text { agree }\end{array}$ \\
\hline $\begin{array}{l}\text { made me think about the care for } \\
\text { infants in general }\end{array}$ & 4.00 & & 1 & 1 & & 1 & 1 \\
\hline $\begin{array}{l}\text { made me think about how to help } \\
\text { infants make the transition from } \\
\text { home to child care }\end{array}$ & 4.50 & & & & 2 & 2 & \\
\hline has taught me new things & 4.50 & & & & 2 & 2 & \\
\hline has been beneficial to the infant & 4.00 & & 1 & & 1 & 2 & \\
\hline $\begin{array}{l}\text { has been beneficial to other } \\
\text { children in the group }\end{array}$ & 3.75 & & 1 & 1 & & 2 & \\
\hline $\begin{array}{l}\text { will be beneficial to future infants } \\
\text { starting child care in my group }\end{array}$ & 4.50 & & & & 2 & 2 & \\
\hline
\end{tabular}




\section{Table 6}

Group Mean Scores, Range and Sample Size for the Intervention $(n=3)$ and Control Group $(n=5-7)$ at the Pre-Test and Post-Test Visit.

\begin{tabular}{|c|c|c|c|c|c|c|c|c|}
\hline \multirow{2}{*}{$\begin{array}{l}\text { Outcome measures } \\
\text { Professional caregiver }\end{array}$} & \multicolumn{2}{|c|}{$\begin{array}{l}\text { Mean and range pre-test } \\
\text { intervention group }\end{array}$} & \multicolumn{2}{|c|}{$\begin{array}{l}\text { Mean and range post- } \\
\text { test intervention group }\end{array}$} & \multicolumn{2}{|c|}{$\begin{array}{l}\text { Mean and range pre-test } \\
\text { control group }\end{array}$} & \multicolumn{2}{|c|}{$\begin{array}{l}\text { Mean and range post- } \\
\text { test control group }\end{array}$} \\
\hline & & & & & & & & \\
\hline Sensitivity play situation & 7.50 & $\begin{array}{c}7.00-8.00 \\
(n=3)\end{array}$ & 6.33 & $\begin{array}{l}5.50-7.50 \\
\quad(n=3)\end{array}$ & 6.42 & $\begin{array}{l}5.00-7.50 \\
\quad(n=6)\end{array}$ & 6.92 & $\begin{array}{l}5.00-8.00 \\
\quad(n=6)\end{array}$ \\
\hline Cooperation play situation & 7.17 & $\begin{array}{l}6.00-8.50 \\
\quad(n=3)\end{array}$ & 6.17 & $\begin{array}{l}4.00-8.50 \\
\quad(n=3)\end{array}$ & 7.25 & $\begin{array}{l}6.00-8.50 \\
\quad(n=6)\end{array}$ & 7.17 & $\begin{array}{c}6.00-9.00 \\
\quad(n=6)\end{array}$ \\
\hline Sensitivity caregiving situation & 7.00 & $\begin{array}{c}6.00-8.00 \\
\quad(n=3)\end{array}$ & 7.33 & $\begin{array}{l}6.50-8.50 \\
\quad(n=3)\end{array}$ & 6.70 & $\begin{array}{l}5.00-9.00 \\
\quad(n=5)\end{array}$ & 7.10 & $\begin{array}{l}6.00-8.00 \\
\quad(n=5)\end{array}$ \\
\hline Cooperation caregiving situation & 8.17 & $\begin{array}{c}7.00-9.00 \\
(n=3)\end{array}$ & 7.33 & $\begin{array}{l}6.50-8.00 \\
\quad(n=3)\end{array}$ & 8.10 & $\begin{array}{c}7.00-9.00 \\
(n=5)\end{array}$ & 7.00 & $\begin{array}{l}6.00-8.00 \\
\quad(n=5)\end{array}$ \\
\hline Quality of care towards infant & & & 4.67 & $\begin{array}{l}4.44-4.89 \\
\quad(n=3)\end{array}$ & & & 4.42 & $\begin{array}{c}4.00-5.00 \\
\quad(n=5)\end{array}$ \\
\hline Quality of care towards parent & & & 4.44 & $\begin{array}{l}3.67-5.00 \\
\quad(n=3)\end{array}$ & & & 4.40 & $\begin{array}{c}4.00-5.00 \\
\quad(n=5)\end{array}$ \\
\hline \multicolumn{9}{|l|}{ Infant } \\
\hline Well-being & 3.78 & $\begin{array}{c}2.50-4.50 \\
\quad(n=3)\end{array}$ & 4.00 & $\begin{array}{c}4.00-4.00 \\
\quad(n=3)\end{array}$ & 3.98 & $\begin{array}{c}2.50-4.50 \\
\quad(n=7)\end{array}$ & 4.10 & $\begin{array}{c}3.00-4.67 \\
(n=7)\end{array}$ \\
\hline Secure base behavior & & & 4.86 & $\begin{array}{l}4.61-5.18 \\
\quad(n=3)\end{array}$ & & & 5.20 & $\begin{aligned} 4.84 & -5.75 \\
(n & =5)\end{aligned}$ \\
\hline \multicolumn{9}{|l|}{ Parent } \\
\hline Separation anxiety & 2.33 & $\begin{array}{l}1.90-2.81 \\
\quad(n=3)\end{array}$ & 1.90 & $\begin{array}{l}1.43-2.14 \\
\quad(n=3)\end{array}$ & 2.50 & $\begin{array}{l}2.19-2.81 \\
\quad(n=5)\end{array}$ & 2.29 & $\begin{aligned} 2.19 & -2.52 \\
(n & =5)\end{aligned}$ \\
\hline
\end{tabular}

